\title{
Haemodynamic Changes During Graded Exercise in Patients with Diabetic Autonomic Neuropathy
}

\author{
J.Hilsted ${ }^{1,2}$, H.Galbo ${ }^{1}$, N.J.Christensen ${ }^{3}$, H.-H.Parving ${ }^{5}$, and J. Benn ${ }^{4}$ \\ ${ }^{1}$ Institute of Medical Physiology B, University of Copenhagen, ${ }^{2}$ Hvidøre Hospital, ${ }^{3}$ Department of Internal Medicine and Endocrinology, \\ Herlev Hospital, ${ }^{4}$ Steno Memorial Hospital, and ${ }^{5}$ Department of Clinical Physiology and Internal Medicine C, Bispebjerg Hospital, \\ Copenhagen, Denmark
}

Summary. Haemodynamic variables were measured during supine rest and during ergometer cycle exercise at two work loads ( $50 \mathrm{~W}$ and $100 \mathrm{~W}$ ) in normal subjects $(n=7)$, in insulin-dependent diabetic subjects without neuropathy $(n=8)$, in insulin-dependent diabetic subjects with slight autonomic neuropathy (decreased beat-to-beat variation in heart rate, which is considered due to a cardiac parasympathetic defect; $n=8$ ), and in insulin-dependent diabetic subjects with severe autonomic neuropathy, including orthostatic hypotension $(n=7)$. Compared with normal subjects, cardiac stroke volume was lower in the diabetic subjects with autonomic neuropathy, both at rest and during exercise $(p<0.025)$, whereas intermediate values were found in the diabetic subjects without neuropathy. The increase in cardiac output in response to exercise was smaller $(p<0.05)$ in both diabetic groups with autonomic neuropathy compared with the normal and diabetic subjects without autonomic neuropathy. The increase in hepato-splanchnic vascular resistance was smaller in the diabetic subjects with severe autonomic neuropathy than in the normal subjects and the diabetic subjects without autonomic neuropathy ( $p<0.025$ ), whereas intermediate values were found in the diabetic subjects with slight autonomic neuropathy. We conclude that, in diabetic patients with severe autonomic neuropathy, the responses of the heart and the splanchnic resistance vessels to exercise are impaired. While sympathetic neuropathy may be responsible for impaired function of splanchnic resistance vessels, both cardiac sympathetic neuropathy and diabetic cardiomyopathy may be involved in the impaired cardiac response to exercise in diabetic subjects with autonomic neuropathy.

Key words: Insulin-dependent diabetes, autonomic neuropathy, graded exercise, heart rate, blood pres- sure, cardiac output, cardiac stroke volume, plasma volume, hepato-splanchnic blood flow, body temperature, plasma catecholamines.

We have reported previously [1] that the capacity for graded exercise, both as the maximally tolerable work load and the maximal oxygen uptake $\left(\dot{\mathrm{V}}_{\mathrm{O}_{2}} \max \right)$, is reduced in insulin-dependent diabetic subjects with signs of autonomic neuropathy (i.e. decreased beatto-beat variation in heart rate during hyperventilation due to cardiac parasympathetic neuropathy [2]. Measurement of plasma concentrations of catecholamines suggested that during exercise, the activity in sympathetic nerves to the heart and to resistance vessels (arteries and arterioles) is impaired in diabetic patients with decreased beat-to-beat variation [3].

The aim of the present study was to determine directly whether cardiac output and hepato-splanchnic vascular resistance during graded exercise are altered in diabetic patients with autonomic neuropathy compared with those without neuropathy. During exercise, temperature regulation depends on the redistribution of blood flow and volume and on activation of sweat glands [4]. Since these changes are mediated by sympathetic nervous activity and may be affected by autonomic neuropathy, we have also measured core and skin temperature during exercise.

\section{Material and Methods}

\section{Patients}

Twenty-three insulin-dependent male diabetic patients and seven healthy males volunteered for the study after giving written, informed consent (Table 1). The patients were divided into three 
Table 1. Clinical characteristics of the subjects studied

\begin{tabular}{|c|c|c|c|c|c|c|c|c|c|c|}
\hline & $\begin{array}{l}\text { Age } \\
\text { (years) }\end{array}$ & $\begin{array}{l}\text { Duration } \\
\text { of } \\
\text { diabetes } \\
\text { (years) }\end{array}$ & $\begin{array}{l}\text { Daily } \\
\text { insulin } \\
\text { dose } \\
\text { (IU) }\end{array}$ & $\begin{array}{l}\text { Height } \\
\text { (cm) }\end{array}$ & $\begin{array}{l}\text { Weight } \\
(\mathrm{kg})\end{array}$ & $\begin{array}{l}\text { Vibration } \\
\text { sense } \\
\text { threshold } \\
\text { (V) }\end{array}$ & $\begin{array}{l}\text { Heart rate } \\
\text { variation } \\
\text { (beats/min) }\end{array}$ & $\begin{array}{l}\text { Serum } \\
\text { creatinine } \\
(\mu \mathrm{mol} / 1)\end{array}$ & $\begin{array}{l}\text { No. of } \\
\text { patients } \\
\text { with } \\
\text { protein- } \\
\text { uria }\end{array}$ & $\begin{array}{l}\text { No. of } \\
\text { patients with } \\
\text { proliferative } \\
\text { retinopathy }\end{array}$ \\
\hline \multirow{4}{*}{$\begin{array}{l}\text { Normal } \\
\text { subjects } \\
\text { Group } 1 \\
(n=8) \\
\text { Group } 2 \\
(n=8) \\
\text { Group } 3 \\
(n=7)\end{array}$} & $\begin{array}{l}30 \\
(23-34)\end{array}$ & - & - & $182 \pm 2$ & $74 \pm 2$ & $6 \pm 1$ & $30 \pm 4$ & - & - & - \\
\hline & $\begin{array}{l}27 \\
(23-36) \\
36\end{array}$ & $16 \pm 1$ & $39 \pm 3$ & $180 \pm 2$ & $72 \pm 2$ & $7 \pm 1$ & $32 \pm 3$ & $84 \pm 2$ & 0 & 0 \\
\hline & $\begin{array}{l}(27-47) \\
40\end{array}$ & $20 \pm 3$ & $37 \pm 2$ & $176 \pm 2$ & $67 \pm 1$ & $23 \pm 3$ & $8 \pm 2$ & $86 \pm 4$ & 4 & 5 \\
\hline & $(29-49)$ & $19 \pm 3$ & $36 \pm 3$ & $176 \pm 2$ & $67 \pm 3$ & $23 \pm 4$ & $4 \pm 2$ & $93 \pm 6$ & 4 & 4 \\
\hline
\end{tabular}

Age is given as mean and range, other parameters as mean \pm SEM

Group 1:patients without neuropathy. Group 2: patients with decreased beat-to-beat variation in heart rate. Group 3:patients with decreased beat-to-beat variation in heart rate and orthostatic hypotension. Vibratory perception threshold is given in volts, a threshold above 20 volts being indicative of somatic neuropathy

groups according to their beat-to-beat variation in heart rate during hyperventilation [2] and to previously determined blood pressure changes during shift of body position from supine to standing. Four groups were thus studied: Group $1(n=8)$ : patients with normal beat-to-beat variation in heart rate $(>15$ beats $/ \mathrm{min})$ and normal orthostatic blood pressure responses (decrease in systolic blood pressure $\leqslant 15 \mathrm{mmHg} 1 \mathrm{~min}$ after standing up); Group 2 $(n=8)$ : patients with signs of autonomic neuropathy (beat-to-beat variation $\leqslant 15$ beats $/ \mathrm{min}$ ) but having normal orthostatic blood pressure responses; Group 3 $(n=7)$ : patients with decreased beatto-beat variation and orthostatic hypotension (decrease in systolic blood pressure $\geqslant 30 \mathrm{mmHg} 1 \mathrm{~min}$ after standing up). Threshold for vibration sense [5] was elevated in groups 2 and 3 , while normal values were found in group 1 (Table 1$)$; Normal subjects $(n=7)$ : seven healthy males (Table 1).

The duration of diabetes was similar in the three patient groups. Group 1 patients had no clinical signs or symptoms of neuropathy. Two patients in group 2 were impotent and one had retrograde ejaculation; two of these patients also lacked sweat secretion on their feet and legs. Two other group 2 patients had loss of sweat secretion on their feet and legs, but had no other clinical symptoms of neuropathy. In contrast, group 3 patients had gross clinical symptoms of neuropathy: five patients were impotent, six patients had sweating abnormalities as described above, four patients had atrophy of the interdigital muscles and six patients had paraesthesiae. The prevalence of additional long-term complications is given in Table 1.

None of the subjects studied had signs or symptoms of other endocrine, metabolic or cardiovascular diseases, nor were they given any therapy apart from insulin.

\section{Methods}

Diabetic control was optimised during the $24 \mathrm{~h}$ before the study. The last dose of insulin was given at $2200 \mathrm{~h}$, the night before the study. The subjects were studied as outpatients at $0800 \mathrm{~h}$, fasting with at least $12 \mathrm{~h}$ abstention from tobacco and alcohol. They were weighed and a cannula was inserted into a cubital vein in each arm, whereupon they rested supine for $85 \mathrm{~min}$. They then sat resting for $15 \mathrm{~min}$ on an electronically braked ergometer cycle (Siemens Elema $380 \mathrm{~B}$, Stockholm, Sweden), followed by exercise for $20 \mathrm{~min}$ at $50 \mathrm{~W}$. After 15 min supine rest and 15 min rest sitting, they exercised for $20 \mathrm{~min}$ at $100 \mathrm{~W}$. The following parameters were measured at rest and during exercise:

Blood pressure was measured by the indirect auscultatory method, using a sphygmomanometer and a cuff. Blood pressure was measured twice at $15 \mathrm{~min}$ interval supine and after $15 \mathrm{~min}$ exercise at each of the two work loads. Diastolic blood pressures were impossible to measure during exercise.

Heart rate was recorded from surface electrodes, using both an ECG and a cardiotachogram, displayed on an ultraviolet recorder (Abem Ultralette 5651, Abem Instrument Group, Stockholm, Sweden). The mean heart rate in 20 s periods was calculated.

Plasma volume was measured supine with ${ }^{125}$ I-labelled human serum albumin, and its changes during exercise were calculated from the peripheral haematocrit [6] as:

Plasma volume $=$

erythrocyte volume $\times(100$-haematocrit $\times 0.91)$ haematocrit $\times 0.91$

(The factor 0.91 was used to calculate the body haematocrit from the venous haematocrit).

Cardiac output was measured by a freon- 22 rebreathing method $(7,8)$ from the rate of freon 22 wash-in into pulmonary capillaries. The subjects rebreathed (10-15 forced respirations) from a rubber bag (4 litre antistatic). The bag contained 2.5 litre of a gas mixture of $4 \%$ freon, $15 \%$ neon, $1 \%$ argon, $37 \%$ oxygen, and $43 \%$ nitrogen (cardiac output measurements at rest at $50 \mathrm{~W}$ exercise), or of $4 \%$ freon, $13 \%$ neon, $1 \%$ argon, $45 \%$ oxygen, and $37 \%$ nitrogen (cardiac output measurements at $100 \mathrm{~W}$ exercise). Gas was sampled for continous analysis in a quadropol 8-channel mass spectrometer (Centronic MGA 200, 20th Century Electronics, Croydon, UK). Cardiac output was calculated from these data [7] with certain modifications [8]. Coefficient of variation, in 12 measurements on separate days of cardiac output, in a normal subject in the resting supine position was $8 \%$, at $50 \mathrm{~W}$ exercise $7 \%$ and at $100 \mathrm{~W}, 8 \%$. In the present study, cardiac output was measured after 50 min of supine rest and after $15 \mathrm{~min}$ of exercise at both work loads.

Oxygen uptake was measured immediately before rebreathing by the Douglas bag method [1] and during rebreathing from the decrease of oxygen content of the rubber bag. Maximal oxygen uptake was not measured for ethical reasons (risk of retinal lesions during maximal effort in those patients with proliferative retinopathy). 
Cardiac stroke volume was calculated from $\frac{\text { cardiac output }}{\text { heart rate. }}$

Pulmonary tissue volume was calculated from the gas tensions during rebreathing from the difference between the distribution space for a water-soluble gas (freon) and a water-insoluble gas (neon) [9]. Coefficients of variation were 7\% (supine rest), 14\% $(50 \mathrm{~W})$ and $18 \%(100 \mathrm{~W})$.

Total peripheral resistance was calculated from: systolic arterial pressure

cardiac output.

Diastolic blood pressures being impossible to obtain during exercise, total peripheral resistance was calculated from the systolic blood pressure and cardiac output and accordingly over-estimated.

Hepato-splanchnic blood flow was estimated from measurements of peripheral Indocyanine green clearance [10]. After $25 \mathrm{~min}$ of supine rest, $3 \mathrm{ml}$ blood were drawn from the right arm into heparinised tubes for preparation of plasma blanks. Five minutes later, $12.5 \mathrm{mg}$ Indocyanine green dissolved in sterile solvent were injected IV into the left arm and 5,8,11,14, and $17 \mathrm{~min}$ later, $3 \mathrm{ml}$ of heparinised blood were drawn from the right arm. At each work load, $12.5 \mathrm{mg}$ Indocyanine green were injected at the onset of exercise and blood samples were subsequently drawn at intervals, as in the supine position. Plasma Indocyanine green concentrations were read spectrophometrically at $805 \mathrm{~nm}$. Spectrophotometric analysis of urine (collected after the experiment) from group 3 patients with added human serum albumin showed that Indocyanine green was not lost in the urine. The plasma Indocyanine green fractional disappearance rate $(\mathrm{k})$ was determined from the regression line for the log plasma concentrations versus time, calculated by the least squares method [10]. Plasma clearance, which varies in parallel with hepatic blood flow, was then calculated as $\mathrm{k} \times$ plasma volume. Estimated hepato-splanchnic vascular resistance was calculated as $\frac{\text { systolic arterial pressure }}{\mathrm{k} \times \text { plasma volume }}$.

Rectal temperature was measured by a heat-conductivity meter (Ellab, Copenhagen, Denmark). Mean skin temperature was calculated from skin temperature measurements [11] with the same apparatus at the sternum, the right shoulder, the lateral part of the right knee and the lateral part of the right ankle. Temperature measurements were made immediately before each exercise period and after $20 \mathrm{~min}$ of exercise at each work load.

Plasma concentrations of noradrenaline and adrenaline: eight $\mathrm{ml}$ blood were taken from the right arm for catecholamine analysis during supine rest and at the end of each exercise period. The blood was placed in iced tubes, containing $16 \mathrm{mg}$ EDTA and $16 \mathrm{mg}$ ascorbic acid. After centrifugation, the supernatant was frozen at $20^{\circ} \mathrm{C}$. Plasma noradrenaline and plasma adrenaline were determined by a double-isotope derivative assay [12] with certain modifications [13].

Glucose concentrations in blood were determined by the hexokinase method [14]. Blood samples for blood glucose were drawn with the subjects resting supine, at the end of exercise at $50 \mathrm{~W}$ and at the end of exercise at $100 \mathrm{~W}$.

Statistical evalution was made by Mann-Whitney's test for unpaired comparisons and by the Wilcoxon matched pairs signedranks test for paired comparisons [15].

\section{Results}

The capacity for graded exercise was significantly reduced in groups 2 and 3 who had varying degrees of autonomic neuropathy. All group 3 patients and four out of eight group 2 patients were exhausted before completion of the $100 \mathrm{~W}$ exercise period, whereas all
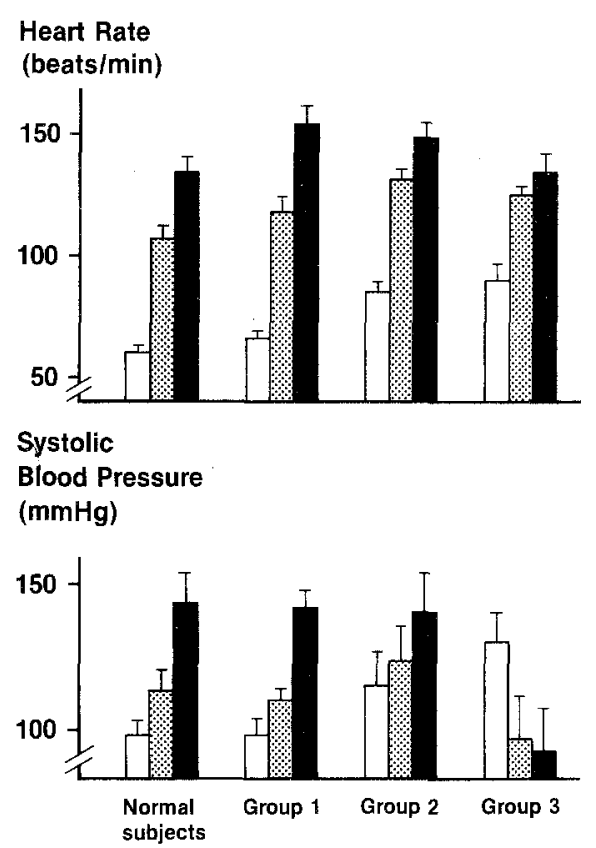

Fig. 1. Heart rate and systolic blood pressure (mean \pm SEM) during supine rest .0 .0 and at the end of two exercise periods $(50 \mathrm{~W} \square$ and $100 \mathrm{~W}$ ). Group 2 and 3 patients were exhausted before completion of the $100 \mathrm{~W}$ work load. In those patients, heart rate and blood pressure at exhaustion were considered representative of maximal values. Normal subjects $(n=7)$, group $1(n=8)$ : diabetic subjects without neuropathy, group $2(n=8)$ : diabetic subjects with one sign of autonomic neuropathy (decreased beat-to-beat variation in heart rate), group $3(n=7)$ : diabetic subjects with decreased beatto-beat variation and orthostatic hypotension

group 1 patients (who did not have neuropathy) and all the normal subjects were able to exercise for $20 \mathrm{~min}$ at $100 \mathrm{~W}$. Therefore, in groups 2 and 3 , results from the $100 \mathrm{~W}$ exercise are given as those obtained either at its completion or at exhaustion (after 5-15 min).

Blood pressure: during supine rest, systolic blood pressure was significantly higher in group 3 patients than in group 1 and normal subjects ( $p<0.05$; Fig. 1$)$. During exercise, systolic blood pressure increased in the normal subjects and in groups 1 and $2(p<0.025)$, whereas no significant changes occurred in group 3 .

Heart rate: resting heart rate was significantly higher in groups 2 and 3 compared with group 1 and the normal subjects $(p<0.01 ;$ Fig. 1$)$. The increase in heart rate during exercise at $50 \mathrm{~W}$ was similar in all groups, whereas the increase in heart rate during exercise at $100 \mathrm{~W}$ was significantly lower in group $3 \mathrm{com}-$ pared with group 1 and the normal subjects $(p<$ 0.05 ). The increase in heart rate during exercise at $100 \mathrm{~W}$ in group 2 was significantly smaller than the increase in group $1(p<0.05)$. Heart rate was not significantly lower at $100 \mathrm{~W}$ in group 3 than in group 2. 
Table 2. Plasma volume and pulmonary tissue volume at rest and during exercise

\begin{tabular}{|c|c|c|c|c|c|c|}
\hline & \multicolumn{3}{|c|}{ Plasma volume $(\mathrm{ml})$} & \multicolumn{3}{|c|}{ Pulmonary tissue volume (ml) } \\
\hline & $\begin{array}{l}\text { Supine } \\
\text { rest }\end{array}$ & $\begin{array}{l}50 \mathrm{~W} \\
\text { exercise }\end{array}$ & $\begin{array}{l}100 \mathrm{~W} \\
\text { exercise }\end{array}$ & $\begin{array}{l}\text { Supine } \\
\text { rest }\end{array}$ & $\begin{array}{l}50 \mathrm{~W} \\
\text { exercise }\end{array}$ & $\begin{array}{l}100 \mathrm{~W} \\
\text { exercise }\end{array}$ \\
\hline Normal subjects $(n=7)$ & $3340 \pm 150$ & $3000 \pm 130$ & $2960 \pm 120$ & $616 \pm 25$ & $670 \pm 96$ & $705 \pm 72$ \\
\hline Group $1(n=8)$ & $3140 \pm 130$ & $2840 \pm 130$ & $2820 \pm 130$ & $574 \pm 28$ & $450 \pm 63$ & $534 \pm 30$ \\
\hline Group $2(n=8)$ & $2820 \pm 150$ & $2580 \pm 40$ & $2570 \pm 50$ & $631 \pm 35$ & $662 \pm 32$ & $687 \pm 93$ \\
\hline Group $3(n=7)$ & $3160 \pm 80$ & $2820 \pm 80$ & $2780 \pm 100$ & $559 \pm 93$ & $507 \pm 73$ & $478 \pm 59$ \\
\hline
\end{tabular}

Results expressed as mean \pm SEM

Table 3. Cardiac output, cardiac stroke volume and oxygen uptake at rest and during exercise

\begin{tabular}{|c|c|c|c|c|c|c|c|c|c|}
\hline & \multicolumn{3}{|c|}{ Cardiac output (1/min) } & \multicolumn{3}{|c|}{ Cardiac stroke volume (ml) } & \multicolumn{3}{|c|}{ Oxygen uptake (ml/min) } \\
\hline & $\begin{array}{l}\text { Supine } \\
\text { rest }\end{array}$ & $\begin{array}{l}50 \mathrm{~W} \\
\text { exercise }\end{array}$ & $\begin{array}{l}100 \mathrm{~W} \\
\text { exercise }\end{array}$ & $\begin{array}{l}\text { Supine } \\
\text { rest }\end{array}$ & $\begin{array}{l}50 \mathrm{~W} \\
\text { exercise }\end{array}$ & $\begin{array}{l}100 \mathrm{~W} \\
\text { exercise }\end{array}$ & $\begin{array}{l}\text { Supine } \\
\text { rest }\end{array}$ & $\begin{array}{l}50 \mathrm{~W} \\
\text { exercise }\end{array}$ & $\begin{array}{l}100 \mathrm{~W} \\
\text { exercise }\end{array}$ \\
\hline $\begin{array}{l}\text { Normal } \\
\text { subjects } \\
(n=7)\end{array}$ & $5.8 \pm 0.4$ & $9.4 \pm 0.7$ & $12.4 \pm 0.8$ & $97 \pm 6$ & $91 \pm 7$ & $96 \pm 8$ & $275 \pm 12$ & $1066 \pm 38$ & $1631 \pm 32$ \\
\hline $\begin{array}{l}\text { Group } 1 \\
(n=8)\end{array}$ & $5.6 \pm 0.6$ & $8.9 \pm 0.3$ & $11.4 \pm 0.5$ & $85 \pm 7$ & $80 \pm 5$ & $75 \pm 4$ & $278 \pm 13$ & $1057 \pm 39$ & $1800 \pm 52$ \\
\hline $\begin{array}{l}\text { Group 2 } \\
(n=8)\end{array}$ & $6.3 \pm 0.5$ & $8.3 \pm 0.4$ & $10.0 \pm 0.8$ & $76 \pm 5$ & $64 \pm 7$ & $68 \pm 5$ & $290 \pm 15$ & $1060 \pm 40$ & $1448 \pm 129$ \\
\hline $\begin{array}{l}\text { Group } 3 \\
(n=7)\end{array}$ & $5.8 \pm 0.6$ & $8.2 \pm 0.4$ & $9.5 \pm 0.6$ & $66 \pm 3$ & $67 \pm 3$ & $69 \pm 3$ & $290 \pm 24$ & $1099 \pm 53$ & $1378 \pm 102$ \\
\hline
\end{tabular}

Results expressed as mean $\pm \mathrm{SEM}$

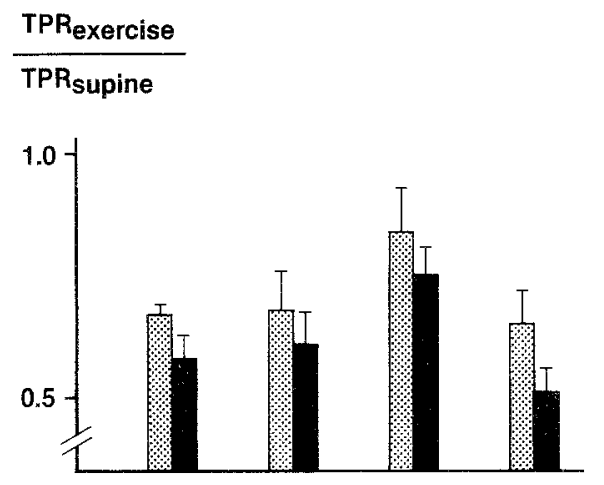

$\frac{\mathbf{R}_{\text {SPL }} \text { exercise }}{\mathbf{R}_{\text {SPL }} \text { supine }}$

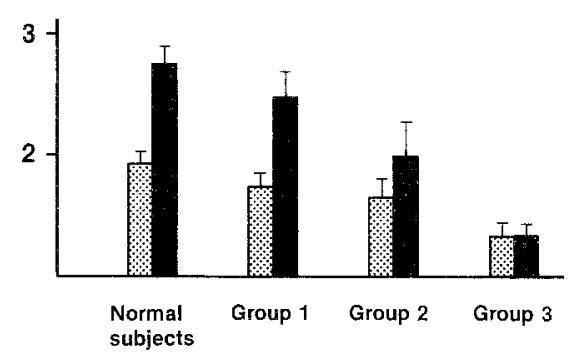

Fig. 2. The ratio between total peripheral vascular resistance (TPR) and hepato-splanchnic vascular resistance $\left(\mathrm{R}_{\mathrm{SPL}}\right)$ (mean $\pm \mathrm{SEM}$ ) during exercise and supine rest in normal subjects and in diabetic patients with different degrees of autonomic neuropathy. : : : $50 \mathrm{~W}$ exercise: supine rest; $100 \mathrm{~W}$ exercise: supine rest
Pulmonary tissue volume and plasma volume: no significant changes or differences between the groups were found in pulmonary tissue volume (Table 2 ). Plasma volume decreased uniformly during exercise in all groups $(p<0.025$; Table 2$)$.

Cardiac output: the increase during exercise at $50 \mathrm{~W}$ was similar in all groups (Table 3 ), whereas the increase during exercise at $100 \mathrm{~W}$ in groups 2 and 3 was significantly lower than in group 1 and the normal subjects $(p<0.05)$. Cardiac output during exercise at $100 \mathrm{~W}$ was significantly lower in group $3 \mathrm{com}-$ pared with the normal subjects $(p<0.05)$.

Cardiac stroke volume was significantly lower, both at rest and during exercise, in groups 2 and 3 compared with the normal subjects $(p<0.025)$, whereas intermediate values were found in group 1 (Table 3).

Oxygen uptake was similar at rest and during exercise at $50 \mathrm{~W}$ in all groups (Table 3 ), whereas oxygen uptake was significantly lower during the $100 \mathrm{~W}$ exercise in groups 2 and 3 compared with group 1 and normal subjects $(p<0.025)$.

Total peripheral resistance and hepato-splanchnic vascular resistance : the ratio of total peripheral resistance during exercise and supine rest was not significantly different in the four groups at either work load. The ratio of hepato-splanchnic vascular resistance 
during exercise and supine rest was significantly lower at both work loads in group 3 compared with group 1 and normal subjects ( $p<0.025)$, whereas intermediate values were found in group 2 (Fig. 2).

Rectal temperature and mean skin temperature: no significant differences were found between the groups, neither at rest nor during exercise.

Plasma concentrations of noradrenaline and adrenaline increased significantly during exercise in all four groups. At $100 \mathrm{~W}$, plasma noradrenaline concentrations were lower in the normal subjects compared with group 1 patients $(p<0.05)$. At this work load plasma noradrenaline concentrations were not significantly different between groups 2 and 3 and group 1 $(p<0.1)$. Plasma adrenaline responses to exercise increased in parallel with those of plasma noradrenaline.

Blood glucose concentrations increased uniformly during exercise in the three diabetic groups. None of the patients had symptoms of hypoglycaemia during exercise. The patients experienced shortness of breath on exhaustion but no episodes of chest pain or arrhythmias occurred.

\section{Discussion}

The finding of a reduced capacity for graded exercise in the diabetic subjects with slight autonomic neuropathy (decreased beat-to-beat variation in heart rate) and those with severe autonomic neuropathy, including orthostatic hypotension, is in accordance with our previous report of a reduced maximal exercise capacity in diabetic patients with decreased beat-to-beat variation [1]. For a given type of exercise in normal subjects, the increased sympathetic outflow to the heart and to resistance vessels is more closely related to the percentage of the maximal oxygen uptake than to the actual work load, whereas cardiac output is related to absolute work load [4]. Therefore, heart rate and splanchnic vascular resistance should be greater in the diabetic subjects with autonomic neuropathy compared with those without neuropathy at the two work loads in this study, as these work loads represent a greater percentage of maximal aerobic capacity in the patients with autonomic neuropathy than in those without neuropathy and in the normal subjects [1]. Thus, the finding of similar or lower responses in the patients with autonomic neuropathy indicates impaired sympathetic outflow in these patients. This is consistent with the finding of similar or lower noradrenaline responses to exercise in the patients with autonomic neuropathy.

Systolic blood pressure decreased during exercise in the group 3 patients (Fig. 1). In patients who have had a thoracolumbar sympathectomy for arterial hypertension [16] or in those who were treated with a ganglion blocking agent (hexamethonium) for arterial hypertension [17], blood pressure has been shown to decrease during exercise. Furthermore, chemical sympathectomy with 6 hydroxy-dopamine in dogs resulted in a fall in blood pressure during exercise [18]. Thus, pharmacological or surgical interruption of the sympathetic outflow impairs the blood pressure response to exercise, probably due mainly to a lack of splanchnic vasoconstriction, which is mediated by sympathetic nerves [4]. Degeneration of the sympathetic nerves has been demonstrated in the splanchnic vascular bed of diabetic patients [19], and this may be responsible for splanchnic vascular resistance not increasing during exercise in groups 2 and 3 in the present study (Fig. 2). Thus, reduced splanchnic vasoconstriction, due to sympathetic neuropathy, may contribute to the absent blood pressure response to exercise in group 3. In addition, the lower increase in cardiac output during exercise in group 3 probably contributed to the blood pressure being lower during exercise in these patients than in the patients without neuropathy. This is suported by the inability of cardiac output to increase during exercise in patients with surgically transplanted hearts also being associated with no increase in blood pressure [20].

Stroke volume was significantly lower during rest and exercise in groups 2 and 3 compared with the normal subjects and their increase in cardiac output was impaired during exercise (Table 3). Since pulmonary tissue volume, which is directly related to central venous pressure [21], was similar in the four groups studied and afterload (blood pressure) was low during exercise in group 3, we conclude that the lower stroke volume during exercise is due to impaired myocardial contractility in this group and probably results either from diminished cardiac adrenergic stimulation or diabetic cardiomyopathy [22]. The latter is supported by the fact that the patients with surgically transplanted and thus denervated hearts are able to increase their stroke volume during exercise by the Frank-Starling mechanism [23].

We conclude that, during graded exercise, the increase in cardiac output is impaired in patients with diabetic autonomic neuropathy due to diminished myocardial contractility and to impaired cardiac acceleration. While impaired cardiac acceleration is probably due to reduced sympathetic stimulation of the heart, because of sympathetic nerve degeneration, diminished myocardial contractility may be due to either sympathetic nerve degeneration or diabetic cardiomyopathy, or both. The increase in hepatosplanchnic vascular resistance was significantly reduced in patients with autonomic neuropathy, prob- 
ably due to splanchnic sympathetic neuropathy. Lack of an increase in blood pressure during exercise in diabetic subjects with severe neuropathy is explained by these defective responses of the heart and the resistance vessels.

Acknowledgements. The study was supported by grants from the Danish Medical Research Council (J. nos. 512-10233, 512-20320, 512-20044 and 512-20131) and from Dr. med. Erik Garde and Elisabeth Gardes Legat. E. Stibolt Jensen, J.Harpøth, L. Kall, H.Overgaard and U. M. Smidt gave skilled technical assistance.

\section{References}

1. Hilsted J, Galbo H, Christensen NJ (1979) Impaired cardiovascular responses to graded exercise in diabetic autonomic neuropathy. Diabetes 28:313-319

2. Hilsted J, Jensen SB (1979) A simple test for autonomic neuropathy in juvenile diabetics. Acta Med Scand 205:385-387

3. Hilsted J, Galbo H, Christensen NJ (1980) Impaired responses of catecholamines, growth hormone, and cortisol to graded exercise in diabetic autonomic neuropathy. Diabetes $29: 257-262$

4. Rowell LB (1974) Human cardiovascular adjustments to exercise and thermal stress, Physiol Rev 54: 75-159

5. Steiness I (1963) Diabetic neuropathy. Vibration sense and abnormal tendon reflexes in diabetics. Acta Med Scand (Suppl) $173: 394-413$

6. Parving H-H, Rossing N, Nielsen SL, Lassen NA (1974) Increased transcapillary escape rate of albumin, IgG, and IgM after plasma volume expansion. Am J Physiol 227: 245-250

7. Triebwasser JH, Johnson RL Jr, Burpo RP, Campbell JC, Reardon WC, Blomqvist CG (1977) Non-invasive determination of cardiac output by a modified acetylene rebreathing procedure utilizing mass spectrometer measurements. Aviat Space Environ Med 48: 203-209

8. Bonde-Petersen F, Norsk P, Suzuki Y (1980) A comparison between freon and acetylene rebreathing for measuring cardiac output. Aviat Space Environ Med 51: 1214-1221

9. Sackner MA, MarkwellG, Atkins N, BirchSJ, FernandezRJ (1980) Rebreathing techniques for pulmonary capillary blood flow and tissue volume. J Appl Physiol 49:910-915

10. Rowell LB, Blackmon JR, Bruce RA (1964) Indocyanine green clearance and estimated hepatic blood flow during mild to maximal exercise in upright man. J Clin Invest 43:1677-1689
11. Ramanathan NL (1964) A new rating system for mean surface temperature of the human body. J Appl Physiol 19:531-533

12. Engelman K, Portnoy B (1970) A sensitive double-isotope derivative assay for norepinephrine and epinephrine. Circ Res 26: $53-57$

13. Christensen NJ (1973) Plasma noradrenaline and adrenaline in patients with thyrotoxicosis and myxoedema. Clin Sci 45 : 163-171

14. Schmidt FH (1961) Die enzymatische Bestimmung von Glucose und Fructose nebeneinander. Klin Wochenschr 39: 1244-1247

15. SiegelS (1956) Nonparametric statistics for the behavioral sciences. McGraw-Hill Kogakusha London

16. Lord JW Jr, Hinton JW (1945) Effect of exercise on blood pressure of patients with advanced hypertension. J Am Med Assoc 129: $1156-1158$

17. Rønnov-Jessen V (1953) Blood pressure and pulse-rate variations during exercise in hypertensives treated with hexamethonium. Nordisk Medicin 50;1356-1360

18. Bassenge E, HoltzJ, Restorff W v, Oversohl K (1973) Effect of chemical sympathectomy on coronary flow and cardiovascular adjustment to exercise in dogs. Pflügers Arch 341: 285-296

19. Low PA, Walsh JC, Huang CY, McLeod JG (1975) The sympathetic nervous system in diabetic neuropathy: A clinical and pathological study. Brain 98:341-356

20. Robinson BF, Epstein SE, BeiserGD, BraunwaldE (1966). Control of heart rate by the autonomic nervous system. Circ Res 19:400-411

21. Weissler AM, McCraw BH, Warren JV (1969) Pulmonary blood volume determined by a radioactive tracer technique. J Appl Physiol 14:531-534

22. Sanderson JE, Brown DJ, Rivellese A, Kohner E (1978) Diabetic cardiomyopathy? An echocardiographic study of young diabetics. Br Med J 1: 404-407

23. Kent KM, CooperT (1974) The denervated heart. New Engl J Med 290: 1017-1021

Received: 1 April 1981

and in revised form: 4January 1982

Jannik Hilsted, M.D.

Institute of Medical Physiology B

University of Copenhagen

Panum Institute

3C Blegdamsvej

DK-2200 Copenhagen N, Denmark 